\title{
Generalized Fibonacci Numbers And Music
}

\author{
Anthony G. Shannon ${ }^{\mathrm{a}}$, Irina Klamka ${ }^{\mathrm{b}}$, Robert van Gend ${ }^{\mathrm{c}}$ \\ a Honorary Fellow, Warrane College, the University of New Sotuh Wales, PO Box 123, Kensington, NSW 1465, \\ Australia, Trustee \& Governor, University of Notre Dame Australia \\ ${ }^{b}$ Lecturer in Music, Australian Institute of Music, 1 Foveaux Street, Surry Hills, NSW 2010, Australia \\ 'School of Philosophy \& Theology, Sydney, University of Notre Dame Australia, 140 Broadway, Chippendale, \\ NSW 2001, Australia \\ irinaklamka@me.com, tony.Shannon@aim.edu.au,tshannon38@gmail.com, \\ r.vangend@student.campion.edu.au
}

\begin{abstract}
Mathematics and music have well documented historical connections. Just as the ordinary Fibonacci numbers have links with the golden ratio, this paper considers generalized Fibonacci numbers developed from generalizations of the golden ratio. It is well known that the Fibonacci sequence of numbers underlie certain musical intervals and compositions but to what extent are these connections accidental or structural, coincidental or natural and do generalized Fibonacci numbers share any of these connections?
\end{abstract}

Indexing terms/Keywords: Fibonacci Numbers, Golden Ratio, Lucas Numbers, Binet Formula, Simson's Identity.

Academic Discipline And Sub-Disciplines: Mathematics: Number Theory, Musicology

Subject Classification: 00A65 [Mathematics and music], 11B39 [Fibonacci and Lucas numbers and generalizations]

Type (Method/Approach): This paper outlines some of the scope and limitations of the Fibonacci sequence of numbers and the GoldenRratio with music. It raises the question of whether these connections are coincidental or substantial; if the latter, the question is can they be extended to generalizations of the Fibonacci numbers developed from extensions of the Golden Ratio.

Language: English

Date of Submission: 2018-04-09

Date of Acceptance: 2018-04-20

Date of Publication: 2018-04-30

ISSN: 2347-1921

Volume: 14 Issue: 01

Journal: Journal of Advances in Mathematics

Website: https://cirworld.com

This work is licensed under a Creative Commons Attribution 4.0 International License. 


\section{INTRODUCTION}

Mathematics seems to be a language through which scientists can understand some aspects of the nature of the universe, but the extent to which numbers can explain the ephemeral experience of music has yet to be fully explored. Music is a language which exists as numbers in time;

- combination of melody (a succession of notes arranged horizontally),

- harmony (the vertical combination of notes to produce chords),

- timbre (the tone colour),

- dynamic (variation of loudness and softness),

- texture (voices)

- tonality (the key), and, most importantly,

- rhythm (the grouping of notes to form defined time patterns)

It is well known that the Fibonacci sequence of numbers and associated golden ratio underlie certain musical intervals and compositions [1]. Are these connections accidental or structural, coincidental or natural? The question is not trivial because aspects of the literature challenge common claims from both a mathematical [2] and musical point of view [3].

Music itself has rules related to certain mathematical principles. "Notwithstanding all the experience I may have acquired in music from being associated with it for so long, I must confess that only with the aid of mathematics did my ideas become clear and did light replace a certain obscurity of which I was unaware before" (Jean-Philippe Rameau quoted in [4]). The Fibonacci numbers have certain established connections with music either directly or indirectly through other mathematical topics such as the golden section [5], continued fractions [6], Pythagorean triples [7] and Farey fractions [9] (for instance, Farey was one of the discoverers of a process for tuning keyboards in equal temperament: in order to obtain one equal tempered interval, one must tune eight intervals by eliminating beats. The fifths and fourths are not so hard, but tuning a major third by eliminating beats is considered difficult.

The mention of 'fourths' suggests Lucas numbers might also be involved, and so the point of this paper is to ask whether generalized Fibonacci numbers also have theoretical connections which are fundamentally related to music. It is beyond the scope of the paper to do more than tease out some of the issues.

\section{MATHEMATICS AND MUSIC}

Pythagoras established the mathematical basis for a musical scale by focusing on intervals:

- octave (division in half),

- perfect fifth (division at two- third),

- perfect fourth (division at three-quarters),

where the core of his interest was an interval between the perfect fourth and perfect fifth. He called this interval a tone. This leads to the understanding that the octave is divided into two tetrachords, which allowed Pythagoras to divide each tetrachord into two tones and semitone, which he called hemitone. The result is the modern diatonic C major: T-T-S-T-T-T-S; only one scale existed at that time.

Musical structures can be expressed as fractions, ratios and proportions. Musicians use basic mathematic knowledge to play rhythm accurately. All divisions of the beat and fraction are expressed by different note length values:

- whole (semibreve),

- half (minim),
- dotted half (dotted minim),

- quarter (crotchet), 
- eighth (quaver),

- sixteenth (semiquaver),
- thirty-second (demisemiquaver),

- sixty- fourth (hemidemisemiquaver).

Those note lengths are exact proportions of a whole note, operating in the same way as fractions.

Cognitive similarity exists between intellectual skills and mental stimulation provided by mathematics and music. Music and mathematics are related in the way symbols, numbers and notes are organized and displayed logically. In music numbers are used in the same way as in mathematics, to describe, to teach, and to compose. It is important for musicians to understand the relationship and values of fractions in order to correctly hold a note. For example, in Common time, if whole (semibreve) note lasts through a bar (measure), while it is equivalent to four quarter (chrothets) notes, it can be expressed mathematically as $4 \times 1 / 4=1$. A quarter (crotchet) with dot after it would be held for $3 / 8$ of measure. Keeping in mind that $4 \times$ quarter (crotchet) $=$ whole (semibreve) note, $8 \times$ eights (quavers) $=$ whole (semibreve) note, and dot makes note half longer of the note which precedes it, dotted quarter (crothet) can be expressed mathematically in the following ways:

$$
1 / 4+1 / 2(1 / 4)=3 / 8, \text { or } 1 / 4+(1 / 4) / 2=3 / 8, \text { or } 1 / 4+1 / 8=3 / 8
$$

Another example: any note can be divided into three equal parts instead of two. A whole (semibreve) note can be divided so as to contain three halves (minims), a half (minim) to contain three quarters (crothets), a quarter (crotchet) three eights (quavers), an eights (quaver), three sixteenth, and so on. These groups are referred to as Triplets. This division is indicated by a group in sets of three, each with the number three over or under them. It is possible to substitute fractions by notes' names and add or substruct according to mathematical rules; for instance, take six eights (quavers) from a whole (semibreve) and write the reminder as one note. $1-6 / 8=2 / 8$ $=1 / 4$. The answer is a quarter (crotchet) note.

Music exists in Time. The word 'Time' describes rhythmic divisions in music, so the Rhythm is the movement of music in Time with regular recurring accents. Regular accent is shown in notation by the bar line drawn through the stave, dividing it into sections of equal time value. The music between the bar lines is called bar or measure. Subdivisions of the bar are called beats or pulses. The composer can choose any number of beats in a bar: two, three, or four in a bar, corresponding to Duple, Triple, Quadruple time, which is expressed in notation by two numbers, called Time Signature. Although numbers appearing as one number above the other, they do not represent a fraction. The top number represents a number of beats in each bar, the bottom number indicates the value of each beat. For example: $2=$ half note $(\operatorname{minim}), 4=$ quarter note (crotchet), $8=$ eight note (quaver). The Time Signature also implies the subdivision of the bar, where some beats are stronger than others; it also implies the grouping of notes. According to the subdivision of the beat, Time Signature is classified as Simple Time, where beat is subdivided into halves or Compound Time, where beat can be subdivided into thirds.

One of the closest links or connections between music and mathematics is the Pattern. The same Pattern recognition applies in chess play: positioning, special relationship, resolving tension. One of the examples of typical Pattern created in music are Cadences. The meaning of this pattern is to emphasise arrival of the end of a phrase, or the end of composition, what in chess would be checkmate, end of the game and in mathematics, it would be the Answer, Proof, Resolution. Mathematics and Music both can be called Contrapuntal Art blended by Logic. In mathematics, study of the pattern can explain and predict the unknown. Music uses the same strategies. When musicians are looking at the score, they recognize notes and their characteristics and how they relate to each other. Relationships among symbols, numbers, and notes are fundamental in both mathematics and music, a cause of inspiration, devotion and appreciation of great beauty [10]. 
However, the German mathematician Johannes Kepler (1571-1630) criticised the Pythagoreans for relying on numbers and not trusting their own ears, although Kepler himself promoted the understanding of the musical intervals of thirds and sixths, which had been excluded/neglected by Pythagoras as not harmonious enough. His use of proportions in music paralleled his study of planetary motion [11]. In this he had been influenced by Boethius' teaching on the Music of Spheres.

The medieval philosopher Anicius Manlius Severinus Boëthius, Boetius or Boethius (480-520AD), in his 'De Institutione Musica' classified music into three parts: Musica mundana (Music of Spheres, harmony of the macrocosm), Musica humana (harmony of the human body), and spiritual harmony (harmony of the microcos ) and Musica instrumentalist (instrumental music). For Boethius Music was/is pure Order out of Chaos [12]. According to him Music is everywhere in nature where everything is in Harmony and Agreement (the word 'harmonia' coming from the Greek meaning 'to fit together'). The golden ratio or section forms part of this as we note in the next section.

\section{FIBONACCI NUMBERS AND THE OCTAVE SCALE}

Music was one of the four parts of the classical quadrivium which supported, or at least rounded out the trivium in the Greek foundations of the liberal arts. The word 'music' in ancient Greece had a wider meaning than it does now, as it included the idea of ratios of integers as the key to understanding both the visible physical universe and the invisible spiritual universe [13]. Thus the Pythagorean scale was the result of applying the Pythagorean ideal of using only the ratios 2:1 and 3:2 to build the music intervals. The Pythagorean scale was used in mediæval European music from about the eighth to the fourteenth centuries (Stewart [14]).

An octave is the interval between a note and the next instance of that same note name on the piano. In Figure 1 an octave interval is from the $C$ on the left to the $C$ on the right of the keyboard. An octave spans 13 notes. For example, an octave starting on C would include $C, C \#, D, D \#, E, F, F \#, G, G \#, A, A \#, B, C$. This is called a "chromatic" scale. The interval between two consecutive notes in a chromatic scale is a "semitone" interval. A "whole-tone" interval is twice a semitone interval. For example, the interval between $F$ and $G$ in Fig. 1 is a whole-tone. "Major" and "minor" scales span 8 notes in one octave, with a mixture of semitones and whole-tones. For example, an octave major scale starting on $C$ would include $C, D, E, F, G, A, B, C$. On a keyboard there are 8 white keys and 5 black keys. The black keys are grouped in 2 and 3.

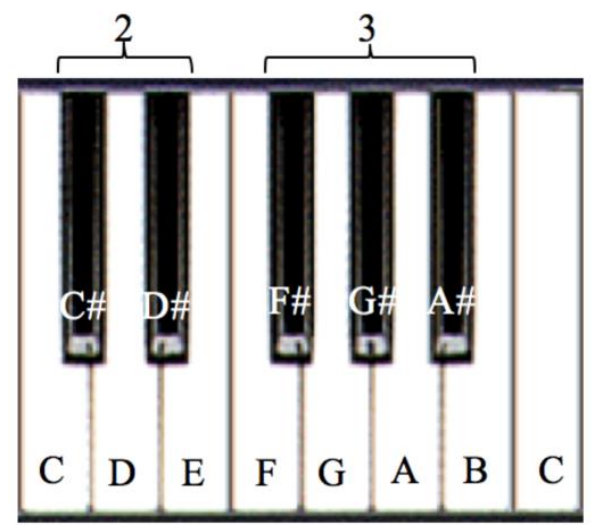

Figure 1: An octave interval 
In the key of $C$, the notes $C, E, G$ are the basic chord of the key, called the root triad. These are 1,3,5 in the scale - Fibonacci numbers. In the octave, the foundational unit of melody and harmony, we see Fibonacci numbers popping up everywhere [15].

The greatest of luthiers, Stradivarius, designed his violins around the golden ratio, $\phi$. His violins are the most valuable and precious instruments in the string-playing world because of their exquisite tonal and harmonic qualities [16]. The Stradivarius violin in Figure 2 reveals how precisely his instruments are determined by the golden ratio [17]:

$$
\frac{a 1+a 2}{a 2}=\frac{a 2}{a 1}=\frac{b 2}{b 1}=\frac{b 2}{c 2}=\frac{c 2}{c 1}=\phi
$$

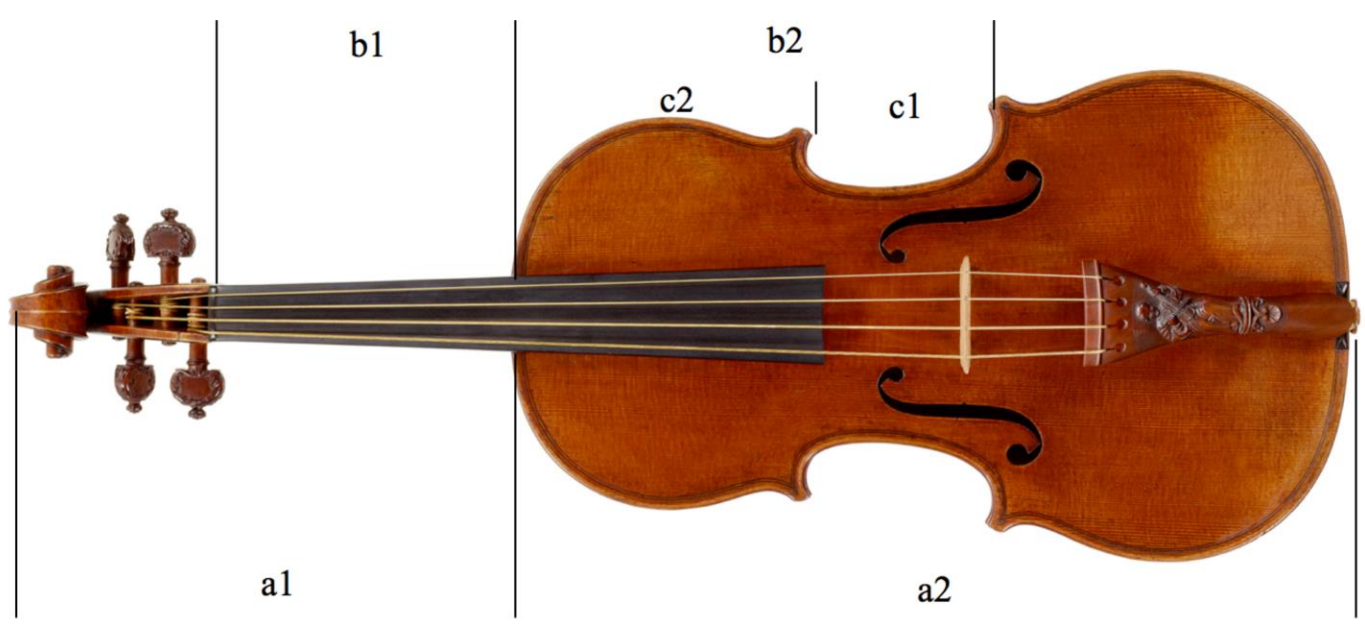

Figure 2. Photo of "Lady Blunt" Stradivarius violin (sold for nearly \$16M).

Photo credits: http://www.bazookaluca.com/2011/07/stradivarius-violins-pizzicato-at-my.html

Roy Howat in his work, Debussy in Proportion: A Musical Analysis, presents his discovery that Debussy's music "contains intricate proportional systems which can account both for the precise nature of the music's unorthodox forms and for the difficulty in defining them in more familiar terms," [18]. These proportional systems are based on the Golden Ratio. For example, Howat notes that the dramatic climax of Cloches a travers les feuilles and of 'Mouvement' from Images (1905) occur exactly on the overall Golden Ratio division of the work; that is, the climaxes occur when the ratio of the total number of bars to the climax bar gives approximately 1.618 .

Howat also postulated that Debussy's preoccupation with Fibonacci numbers explains some of the unorthodox structure of his compositions. As examples he notes:

- the 21 bars introduction to Rondes de Printemps;

- the 34 bars of the $3 / 8$ time section of Jeux;

- the 34 bars build-up to the triumphant coda of L'isle joyeuse and to the recapitulation of Masques; 
- the 34 bars before the first reprise in Reflets dans l'eau and the 55 bars before its climax;

- the 55 bars introduction to the last movement of La mer.

\section{GENERALIZED FIBONACCI NUMBERS}

To what extent are these Fibonacci connections accidental and to what extent are they fundamental? If the latter, could generalized Fibonacci numbers also be involved?

To pose that question more specifically we here consider such numbers in the context of generalized golden sections. It is well-known that the powers of the Golden Section or Ratio, are related to the elements of the Fibonacci sequence, $\left\{F_{n}\right\}$ :

$$
\varphi^{n}=F_{n} \varphi+F_{n-1},
$$

and

$$
\psi^{n}=F_{n+1}-F_{n} \phi,
$$

in which

$$
\psi=1-\varphi .
$$

Similarly for the Lucas sequence, $\left\{L_{n}\right\}$ :

$$
\psi^{n} \Psi=L_{n-1} \psi+L_{n-2},
$$

and

$$
\varphi^{n} \Phi=L_{n}-L_{n-1} \psi
$$

in which

$$
\Psi=\psi+2
$$

and

$$
\Phi=\varphi+2
$$

are the roots of $0=x^{2}-3 x+1$, which is the characteristic polynomial of the second order homogeneous linear recurrence relation

$$
U_{n}=3 U_{n-1}-U_{n-2}
$$

from which even- and odd-suffixed Fibonacci and Lucas numbers can be generated [19,20]. Variations of results for the Golden Section also include the idea that the Golden Ratio may be considered as the first member of a family which can generate a set of generalized Fibonacci sequences. 
Here we relate the ideas there to the work of Filipponi (1991) [21], Monzingo (1980) [22] and Whitford (1977) [23] to consider some related problems with their common thread being the Binet form of these sequences, $\left\{F_{n}(a)\right\}_{\text {, }}$ where the sequence of ordinary Fibonacci numbers can be expressed as $\left\{F_{n}(5)\right\}$ in this notation. Thus, for instance

$$
\frac{F_{n}(a)}{F_{n-1}(a)} \rightarrow \varphi_{a}
$$

in which

$$
\varphi_{a}=\frac{1+\sqrt{a}}{2}
$$

and the generalized Binet formula in this notation is

$$
F_{n}(a)=\frac{\left(\frac{1+\sqrt{a}}{2}\right)^{n}-\left(\frac{1-\sqrt{a}}{2}\right)^{n}}{\sqrt{a}}
$$

which is well-known for the Fibonacci numbers as

$$
F_{n}=\frac{\left(\frac{1+\sqrt{5}}{2}\right)^{n}-\left(\frac{1-\sqrt{5}}{2}\right)^{n}}{\sqrt{5}} .
$$

Hence, elements of the sequences in the family should be similarly predicted. We note in passing that the Binet formula for the Fibonacci numbers is usually attributed to Jacques Philippe Marie Binet (1786-1856), but it was previously known to such famous mathematicians as Abraham de Moivre (1667-1754), Daniel Bernoulli (17001782), and Leonhard Euler (1707-1783): "like many results in Mathematics, it is often not the original discoverer who gets the glory of having their name attached to the result, but someone later!" [24].

When $n$ in Equation (4.7) is a power of 2 we can start to develop identities analogous to those of the Fibonacci sequence. For example,

$$
\begin{gathered}
x^{2 n}-y^{2 n}=\left(x^{n}-y^{n}\right)\left(x^{n}+y^{n}\right) \\
F_{2 n}(a)=F_{n}(a) L_{n}(a)
\end{gathered}
$$

in which $L_{n}(a)$ is the corresponding generalized Lucas sequence. We can continue the process in (4.9) to get 


$$
\begin{aligned}
x^{2 n}-y^{2 n} & =\left(x^{n}+y^{n}\right)\left(x^{n}-y^{n}\right) \\
& =\left(x^{n}+y^{n}\right)\left(x^{\frac{n}{2}}+y^{\frac{n}{z}}\right)\left(x^{\frac{n}{2}}-y^{\frac{n}{2}}\right)
\end{aligned}
$$

and so on. For instance, when $n=4$, this can be reduced to

$$
x^{8}-y^{8}=\left(x^{4}+y^{4}\right)\left(x^{2}+y^{2}\right)(x+y)(x-y)
$$

with $x+y=1$ and $x-y=\sqrt{a}$, and when $n=8$, this can be reduced to

$$
x^{16}-y^{16}=\left(x^{8}+y^{8}\right)\left(x^{4}+y^{4}\right)\left(x^{2}+y^{2}\right)(x+y)(x-y)
$$

or

$$
F_{16}(a)=L_{8}(a) L_{4}(a) L_{2}(a) ，
$$

which can be readily confirmed when $a=5$. More generally,

$$
\frac{x^{n}-y^{n}}{x-y}=\left(x^{n-1}+y^{n-1}\right)+\frac{x y}{x-y}\left(x^{n-2}-y^{n-2}\right)
$$

can be expressed as

$$
F_{n}(a)=L_{n-1}(a)+\left(\frac{1-a}{4}\right) F_{n-2}(a)
$$

which, when $a=5$ and $n=7, F_{7}(5)=13$, and $L_{6}(5)-F_{5}(5)=18-3$. Equation (4.12) can be factorised further

$$
\frac{x^{n}-y^{n}}{x-y}=\left(x^{n-1}+y^{n-1}\right)+\left(\frac{1-a}{4}\right)\left(x^{n-3}-y^{n-3}\right)+\left(\frac{1-a}{4}\right)^{2}\left(x^{n-5}-y^{n-5}\right)+\left(\frac{1-a}{4}\right)^{3}
$$


This in turn can be re-written as

$$
F_{n}(a)=L_{n-1}(a)+\left(\frac{1-a}{4}\right) L_{n-3}(a)+\left(\frac{1-a}{4}\right)^{2} L_{n-5}(a)+\left(\frac{1-a}{4}\right)^{3}
$$

for instance,

$$
F_{7}(5)=L_{6}(5)-L_{4}(5)+L_{2}(5)-1 .
$$

Direct calculations of $\left(\frac{1+\sqrt{a}}{2}\right)^{n}$ and $\left(\frac{1-\sqrt{a}}{2}\right)^{n}$ as in the Binet equation (4.7) and from (4.13) yield the patterns set out in Table 1. Each $n$ yields an infinity of 'golden ratios', and from them we can generate an

\begin{tabular}{|c|c|c|c|c|}
\hline$n$ & $L_{n}(a)$ & $L_{n}(5)$ & $L_{n}(13)$ & $L_{n}(17)$ \\
\hline 2 & $\frac{1}{2^{1}}(a+1)$ & 3 & 7 & 9 \\
\hline 4 & $\frac{1}{2^{3}}\left(a^{2}+6 a+1\right)$ & 7 & 31 & 49 \\
\hline 6 & $\frac{1}{2^{5}}\left(a^{3}+15 a^{2}+15 a+1\right)$ & 18 & 154 & 297 \\
\hline 8 & $\frac{1}{2^{7}}\left(a^{4}+28 a^{3}+70 a^{2}+28 a+1\right)$ & 47 & 799 & 1889 \\
\hline$n$ & $F_{n}(a)$ & $F_{n}(5)$ & $F_{n}(13)$ & $F_{n}(17)$ \\
\hline 3 & $\frac{1}{2^{2}}(a+3)$ & 2 & 4 & 5 \\
\hline 5 & $\frac{1}{2^{4}}\left(a^{2}+10 a+5\right)$ & 5 & 19 & 29 \\
\hline 7 & $\frac{1}{2^{6}}\left(a^{3}+21 a^{2}+35 a+7\right)$ & 13 & 97 & 181 \\
\hline 9 & $\frac{1}{2^{8}}\left(a^{4}+36 a^{3}+126 a^{2}+84 a+9\right)$ & 34 & 508 & 1165 \\
\hline
\end{tabular}
infinity of generalized Golden Ratio Fibonacci numbers, some examples of which are also displayed in Table 2.

Table 1: Various Golden Ratio Sequences 
That is, for example, as in the last line of Table 1 and from Equation (4.14), we have that:

$$
F_{9}(a)=\frac{1}{2^{8}}\left(a^{4}+36 a^{3}++126 a^{2}+84 a+9\right)
$$

so that

$$
u_{9}(5)=34=F_{9}(5), u_{9}(13)=508=F_{9}(13), u_{9}(17)=1165=F_{9}(17)
$$

in which the sequences satisfy a second order recurrence relation in the form

$$
u_{n}(a)=u_{n-1}(a)+\left(\frac{a-1}{4}\right) u_{n-2}(a), n>2,
$$

with unity as the initial terms as in Whitford. Thus Simson's identity becomes

$$
F_{n}(a) F_{n+2}(a)-F_{n+1}^{2}(a)=(-1)^{n+1}\left(\frac{a-1}{4}\right)^{n}
$$

which had previously been proved by Lucas [25]. We shall not explore the underlying mathematics further. Instead we shall briefly consider Whitford's table of sequences which we have slightly adapted and extended (Table 2).

\begin{tabular}{|l|l|l|l|l|l|l|l|l|l|l|l|}
\hline$a$ & $\frac{a-1}{4}$ & $F_{1}(a)$ & $F_{2}(a)$ & $F_{3}(a)$ & $F_{4}(a)$ & $F_{5}(a)$ & $F_{6}(a)$ & $F_{7}(a)$ & $F_{8}(a)$ & $F_{9}(a)$ & $F_{10}(a)$ \\
\hline $\mathbf{1}$ & $\mathbf{0}$ & 1 & 1 & 1 & 1 & 1 & 1 & 1 & 1 & 1 & 1 \\
\hline $\mathbf{5}$ & $\mathbf{1}$ & 1 & 1 & 2 & 3 & 5 & 8 & 13 & 21 & 34 & 55 \\
\hline $\mathbf{9}$ & $\mathbf{2}$ & 1 & 1 & 3 & 5 & 11 & 21 & 43 & 85 & 171 & 341 \\
\hline $\mathbf{1 3}$ & $\mathbf{3}$ & 1 & 1 & 4 & 7 & 19 & 40 & 97 & 217 & 508 & 1159 \\
\hline $\mathbf{1 7}$ & $\mathbf{4}$ & 1 & 1 & 5 & 9 & 29 & 65 & 181 & 441 & 1165 & 2929 \\
\hline $\mathbf{2 1}$ & $\mathbf{5}$ & 1 & 1 & 6 & 11 & 41 & 96 & 301 & 781 & 2286 & 6191 \\
\hline $\mathbf{2 5}$ & $\mathbf{6}$ & 1 & 1 & 7 & 13 & 55 & 133 & 463 & 1261 & 4039 & 11605 \\
\hline
\end{tabular}

Table 2: Whitford's table of Generalized Fibonacci numbers - extended 
Can these be related to music in some fundamental theoretical manner?

\section{FIBONACCI COMPOSITION FOR PIANO}

While not wanting to be compared to the genius of a Debussy, here is a short composition by van Gend (Figure 4) based almost entirely on Fibonacci numbers. ${ }^{1}$ Each note in the scale of $C$ major is numbered (see Figure 3) and the notes that correspond to Fibonacci numbers are used in the composition. Each time the music changes key, the note that corresponds to 1 in the Fibonacci sequence changes. So in D major, note 1 is a $D$ (while in $C$ major it is a $C$ ). The order of notes in the melody is $1,1,2,3,5,8$ with the occasional addition of 13 and 21 .

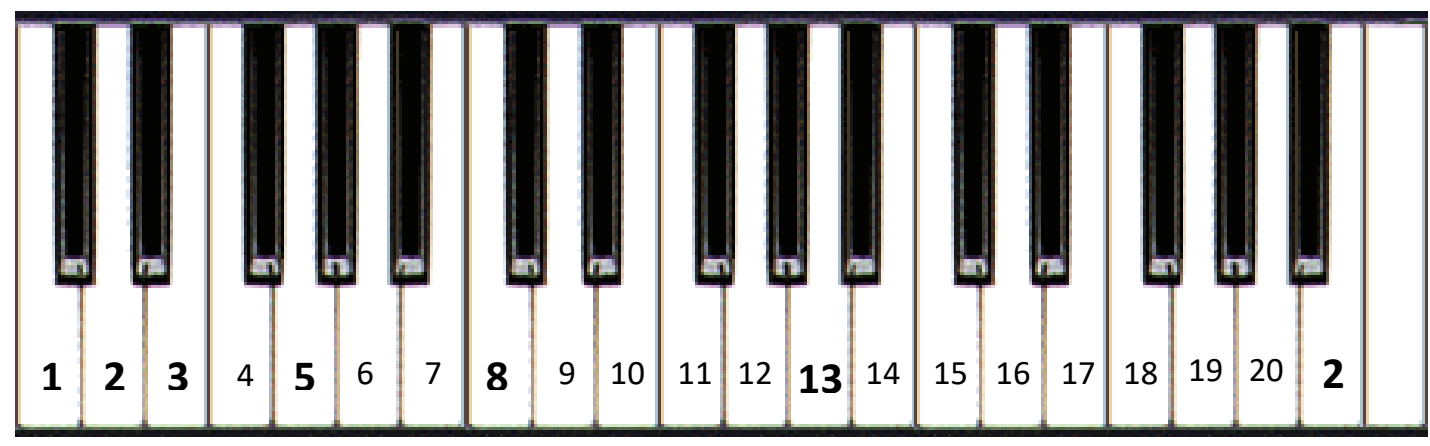

Figure 3: Numbered notes in the scale of $\mathrm{C}$

The work, naturally, is 13 bars long and is structured in phrases of increasing length: 1,1,2,3 and 5 bars. The groups of bars are marked by brackets in the music score (see Figure 4). After the first 1 bar motif, the second is similar but inverted. Then the theme appears for the first time as a 2 bar phrase, repeated as a 3 bar phrase with added bass notes. A 5 bar developed version of the theme is the final phrase, and a short 1 bar imitation of the first bar motif concludes the work. While this structure is far less subtle than the form of Debussy's compositions, it gives the music a clear feeling of "growth".

The theme grows over the course of the work - one can hear in the recording how it sounds "busier" and more developed. It has been made clear on the score how the notes correspond to Fibonacci numbers. The opening bar is a flourish of notes, using all the Fibonacci numbers in order up to 21 . The recurring theme starting in bar 3 uses the notes corresponding to 1,1,2,3,5,8,5,3,2,1. It creates a restful rising and falling tune. In bar 7, a note is used that is not in the Fibonacci sequence. While it makes sense as part of the chord progression in the bass, it sounds less harmonious than the rest of the piece - a "surprise" note. This is an interesting discovery - that a non-Fibonacci note sounds out of place (perhaps even "unnatural") in a piece completely full of Fibonacci notes. In bar $12 \mathrm{I}$ break up the order of the Fibonacci notes for variety and to help with modulating to the new key. Instead of 1,3,5,8, it becomes 3,1,5,3,8. It has a similar growing sense to it and the notes harmonise well in the progression.

Bar 11 begins a progression of keys. It starts in $C$ major (as indicated on the score) which is number 1 as a Fibonacci note. The music modulates half a bar later to $D$ major, which corresponds to 2 on the Fibonacci sequence. Then the music modulates to $\mathrm{E}$ major (3) and finally $\mathrm{G}$ major (5). So while the notes themselves fly up and down the Fibonacci notes, the overall progression of keys also follows the sequence: $1,2,3,5$. The progression rises well, and has that sense of growth.

\footnotetext{
${ }^{1}$ To hear a recording of the work, visit this link and download the file:

https://docs.google.com/file/d/0Bwb7y3cfmfoeRV9rZTVObkJKbWs/edit?usp=sharing
} 

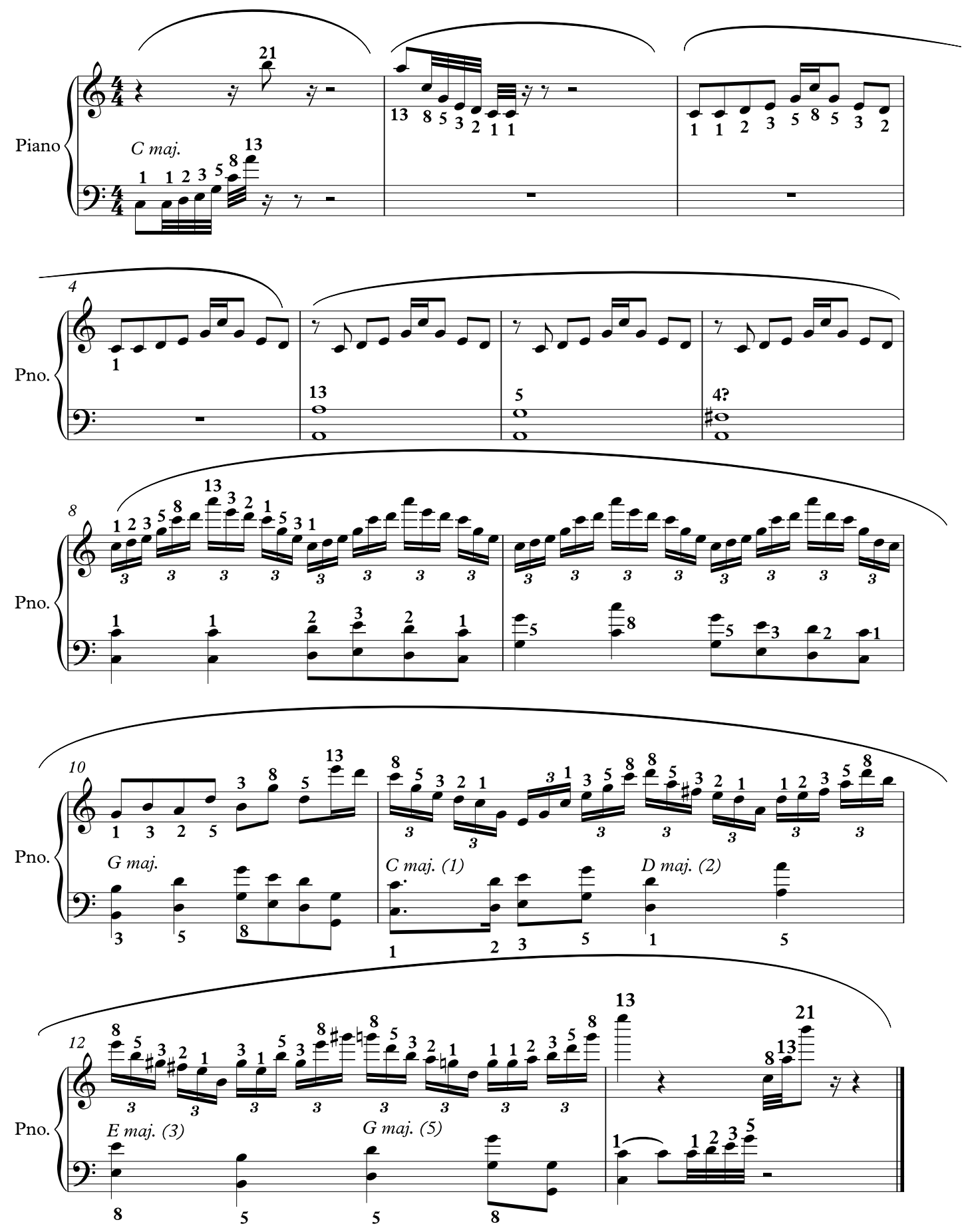

Figure 4: Fibonacci composition (van Gend) 
From this analysis, it is clear that the sequence $\{1,1,2,3,5,8, \ldots\}$ has a distinct growing sound to it. In this work, the theme is repeated and developed over the course of the 13 bars, and this gives the piece a feel of continuous rising and falling while evolving. The overall structure of the work is based on groupings of bars into Fibonacci numbers, which gives the sense of expansion and growth of the whole work. The use of only Fibonacci notes works well for harmonious writing. This was surprising, as it could be difficult to have variety while only using Fibonacci notes. In summary, it seems that the Fibonacci numbers work naturally together in music too.

\section{CONCLUSION}

It is clear that the Fibonacci sequence of numbers and the golden ratio are manifested in music. The numbers are present in the octave, the foundational unit of melody and harmony. Stradivarius used the golden ratio to make the greatest string instruments ever created. Roy Howat's research on Debussy's works shows that the composer used the golden ratio and Fibonacci numbers to structure his music. Haylock [26] describes a number of occurrences of the golden ratio in the first movement of Beethoven's fifth symphony; he poses the question which goes to the heart of this paper: "is this just something which happened by accident, or did Beethoven do it deliberately?",.

The Fibonacci Composition reveals the inherent aesthetic appeal of this mathematical phenomenon. Fibonacci numbers harmonise naturally and the exponential growth that the Fibonacci sequence typically defines in nature is made present in music by using Fibonacci notes.

Of course, music and mathematics share their love of suitable notation [27] and this too opens up other possibilities for more research into deeper connections and appropriate pedagogies in both music and mathematics, which are essential components of the liberal arts and the study of Western civilization [28]. In this sense, other approaches to generalization of the golden ratio are implicit in Section 1.1 of Falcon [29]. Finally, "during the past 40 years, mathematical music theory has grown and developed in both the fields of music and mathematics. In music pedagogy, the need to analyze patterns of modern composition has produced Musical Set Theory, and the use of Group Theory and other modern mathematical structures have become almost as common as the application of mathematics in the fields of engineering or chemistry. Mathematicians have been developing stimulating ideas when exploring mathematical applications to established musical relations. Mathematics students have seen in Music in Mathematics courses, how their accumulated knowledge of abstract ideas can be applied to an important human activity while reinforcing their dexterity in Mathematics" [30].

\section{CONFLICTS OF INTEREST}

The author(s) declare(s) that there are no conflicts of interest regarding the publication of this article.

\section{REFERENCES}

1. Grimaldi, R.P. 2012. Fibonacci and Catalan Numbers: An Introduction. Hoboken, NJ: Wiley.

2. Markovsky, George. 2018. Misconceptions about the Golden Ratio. College Mathematics Journal. 23 (1): 2-19.

3. Tatlow, Ruth. 2006. The Use and Abuse of Fibonacci Numbers and the Golden Section in Musicology Today. Understanding Bach. 1: 69-85.

4. Benson, David I. 2006. Music: a Mathematical Offering. Cambridge: Cambridge University Press, Ch.6. 
5. Putz, J.F. 1995. "The golden section and the piano sonatas of Mozart." Mathematics Magazine. 68 (4): 275-282.

6. $\quad$ Barbour, J.M. 1948. "Music and ternary continued fractions." American Mathematical Monthly. 55 (9): 545-555.

7. Huntley, H.E. 1970. The Divine Proportion: A Study in Mathematical Beauty. New York: Dover, Ch.II.

8. Kramer, Jonathan. 1973. "The Fibonacci series in twentieth-century music." Journal of Music Theory. 17 (1): 110-148.

9. Farey, John. 1807. "On a new mode of equally tempering the musical scale." Philosophical Magazine, 27: 65-66.

10. Larcombe, Peter J. 2018. "A few thoughts on the aesthetics of mathematics in research and teaching." Palestine Journal of Mathematics. 7 (1): 1-8.

11. Kepler, Johannes. 2014. Harmonies of the World. (Translated by Charles Glenn Wallis, 1939; original 1619). @GlobalGrey2014, pp.25-68.

12. Boetius. 2007. Consolation of Philosophy. (Translated by H.R. James). Adelaide: eBooks@Adelaide, Book II,Ch.4.

13. Anderson, Warren D. 1994. Music and musicians in ancient Greece. Ithaca, NY: Cornell University Press.

14. Stewart, lan. 2004. Another fine math you've got me into... New York: Dover, Ch.15.

15. van Gend, Robert. 2014. "Fibonacci numbers and music." Notes on Number Theory and Discrete Mathematics. 20 (1): 72-77.

16. Goldennumber.net. 2012. Acoustics. Online at http://www.goldennumber.net/acoustics/.

17. Yurick, S. 2012. Music and the Fibonacci Series and Phi. online: http://www.goldennumber.net/music.

18. Howat, R. 1983. Debussy in Proportion: A Musical Analysis. Cambridge: Cambridge University Press, p. 1.

19. Leyendekkers, J.V., and A.G. Shannon. 2014. The Decimal String of the Golden Ratio. Notes on Number Theory and Discrete Mathematics. 20 (1): 27-31.

20. Hoggatt, V. E. Jr. 1969. Fibonacci and Lucas Numbers. Boston, MA: Houghton Mifflin.

21. Filipponi, P. 1991. "A Note on a Class of Lucas Sequences." The Fibonacci Quarterly. 29 (3): 256-263.

22. Monzingo, M. G. 1980. "An Observation Concerning Whitford's 'Binet's Formula Generalized'." In A Collection of Manuscripts Related to the Fibonacci Sequence edited by V.E. Hoggatt Jr and Marjorie Bicknell-Johnson. Santa Clara, CA: The Fibonacci Association, pp.93-94.

23. Whitford, A.K. 1977. "Binet's Formula Generalized." The Fibonacci Quarterly. 15(1): 21, 24, 29.

24. Knott, R. 2015. "Fibonacci Numbers and the Golden Section." Available online at: http://www.maths.surrey.ac.uk/hosted-sites/R.Knott/Fibonacci/fib.html 
25. Lucas, E. 1969. The Theory of Simply Periodic Numerical Functions. (Edited by D.A. Lind; translated by S. Kravitz.) San Jose: The Fibonacci Association.

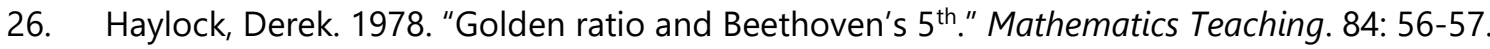

27. Kuijken, Barthold. 2013. The Notation is Not the Music. Bloomington, IN: Indiana University Press, Ch.1.

28. Shannon, Anthony G, and Jean V. Leyendekkers. 2018. The Fibonacci Numbers and Integer Structure. New York: Nova Science Publishers, Chs1,6.

29. Falcon, Sergio. 2018. "Some new formulas on the k-Fibonacci numbers." Journal of Advances in Mathematics. 14 (1): 7439-7445.

30. Montiel, Mariana, and Francisco Gómez (eds). 2018. Theoretical and Practical Pedagogy of Mathematical Music Theory. New Jersey, Singapore, Hong Kong, London: World Scientific, Section I. [https://www.worldscientific.com/ worldscibooks/10.1142/10665.

\section{AUTHORS' BIOGRAPHIES WITH PHOTOS}

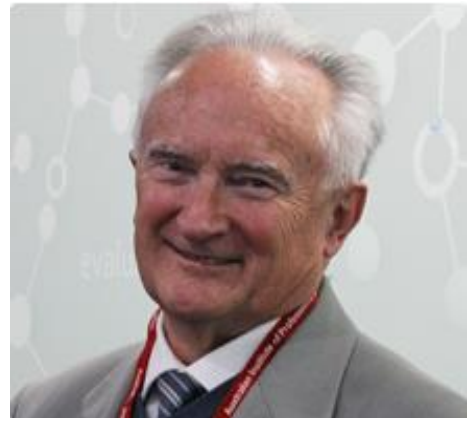

A. G. (Tony) Shannon AM is an Emeritus Professor of the University of Technology Sydney, where he was Foundation Dean of the UTS Graduate Research School and Professor of Applied Mathematics. He has also been Deputy Chancellor of the University of Notre Dame Australia where he is still a Trustee and Governor. He holds the three doctoral degrees of PhD, EdD. and DSc. He was Master of Warrane College, the University of New South Wales for ten years. He is co-author of numerous books and articles in medicine, mathematics and education. He was appointed a Member of the Order of Australia (AM) in the Queen's Birthday honours list of 1987 for services to education, particularly in the field of applied mathematics. He enjoys reading, walking, theatre, watching rugby and thoroughbred racing.

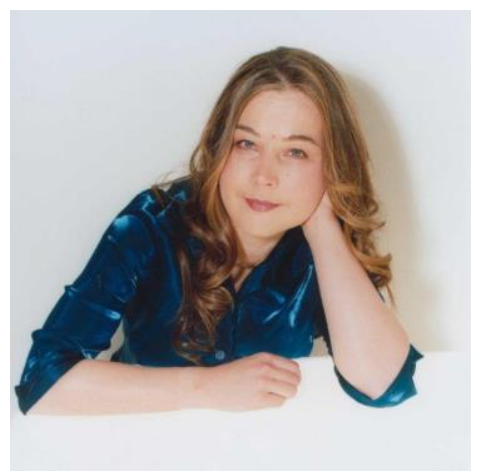

Irina Klamka is an accomplished and highly qualified Piano Teacher, Accompanist and Music lecturer with the Australian Institute of Music. Born and educated in Russia, Irina obtained her DipMus (HD) and BMus (Honours HD) Performance degrees from Saratov State Conservatorium of Music, influenced and developed under the direction of outstanding educators in music from the Russian Piano School of H.G. Newhouse and M.I. Grinberg. In Australia, Irina graduated from Griffith University with a Master of Music Studies. Irina's teaching capabilities were recognised in 2015, 2016 and 2017 with the award of the Certificate of Distinction in the category of Most Outstanding Private Teacher by the Australian Music Examinations Board (NSW). Irina has a life-long passion for music, piano pedagogy, teaching and history. Irina believes that "the study of music is a wonderful, spiritual practice". 


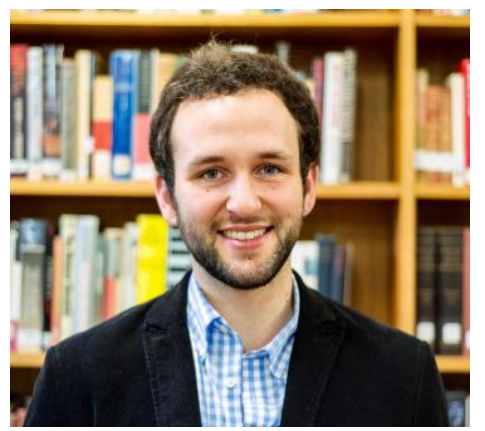

Robert van Gend graduated from Campion College, Sydney in 2014 with the College Medal for the Bachelor of Arts (Liberal Arts), majoring in Philosophy, History and Latin. In 2015 he presented a paper on 'The Christian View of Cosmic History' at a colloquium run by the Christopher Dawson Centre for Cultural Studies in Tasmania, which was later published in Dangerous Ideas (Connor Court, 2017). He is also a published author in the field of mathematics and music and he is currently writing a thesis on the mind-body problem for a Master of Philosophy degree at the University of Notre Dame Australia, Sydney Campus. He is also Dean of Studies and Lecturer in Philosophy at the Augustine Academy, a liberal arts institute near Picton, New South Wales. Robert plays viola with the Australian Youth Orchestra and has received his $L M U$ SA in violin and in ensemble performance. 